\title{
Study on the Development Model of Accounting Mathematics Xiling Liu ${ }^{1}$ \\ ${ }^{1}$ Guangxi Technological College of Machinery and Electricity, Nanning, Guangxi 530007 ${ }^{\mathrm{a} e m a i l,}$
}

Keywords: Accounting Mathematics; Mathematics Tendency; Mathematical Thinking; Cost Accounting

\begin{abstract}
With the development of science and technology, although the mathematics and accounting changes have occurred, there are simultaneous development in the long history of the development process is a trace and a necessarily link, both of them take the "number" as the basis and everything begins from "math". This paper tries to analysis accounting problems with mathematical thinking, make concise analysis. Of course, it will have a huge reaction. Marx pointed out: a science that only successful use mathematics, can it achieve a real improvement of the situation. Then we can say mathematics in many ways to promote the development of accounting.
\end{abstract}

\section{Introduction}

Whether natural science or social science, its emergence and development has its own characteristics, with the development of science, technology, changes in subject areas and its own evolution it can be seen, although mathematics, accounting has transmutation occurs, but in the long process of historical development, there are still traces of their simultaneous development is a necessary connection or statement, are based on "number" as the basis, everything from "several" to start.

In ancient times, whether East or West, when people understand the mathematical understanding of accounting issues published in various papers are almost the same, both descriptive, qualitative, but also quantitative analysis, and sometimes the problem is not tell discussed mathematics accounting field or category, because the two disciplines are so similar, almost identical to the problem narrative, are "quantitative" research, so that scientists in some 18 centuries ago, both called mathematician, also called accounting experts.

Mathematics develop into today's mathematics from elementary mathematics, accounting basis from the original formation of today's accounting numerous accounting branch, such as cost accounting, financial accounting, and professional accounting in various industries. Form and content of various disciplines have been very obvious difference, but "plus, minus" to "borrow, loan" from the "number of tables - Matrix" to "financial statements" from "positive and negative" to "account could not apply when the dual nature "of mathematical knowledge and decision-making accounting program, and both revealed two lingering.

\section{Mathematics Penetration in the Field of Accounting}

From the 19th century, it had been widely used mathematical methods in various disciplines study. And the gradual introduction of the concept of variables and functions, the study of mathematics tendency has unprecedented strengthening. 19 centuries ago, the Institute of Mathematical require substantially exceed "Math" primary computing, with the development of mathematics, and future research already commonly used by the differential, differential equations and other higher mathematics knowledge, more importantly, has generally begun to use mathematical thinking to 
understand the various disciplines, especially the issue of accounting, mathematics has penetrated into all areas of accounting, so that the results of Discussion concise and clear.

Basic Accounting. Accounting taught business economics at the kind of business types for various materials are then obtained from Examples Conclusions: four types, nine cases. Because it is an example, and many economic activities, in the learning process will naturally think of the economic and business types can be exhaustive? There are no exceptions? If we can use mathematical permutations and combinations of knowledge in the learning process to analyze, think, without exhaustive it shows that there is no "exception."

Accounting equation: Assets= equity

Asset $=$ Liabilities + Equity

Wherein each of two or three elements (elements), the impact of economic business on nothing more than accounting elements: increase, decrease or words borrowed two loans, there are two elements (assets, rights and interests by the equation ( I ) in ) choice, when the loan also choose two elements. According to the characteristics of the loans accounting law, "there must have borrowed loans, loans must equal" shows the equation ( I ) A total of $2 \times 2=4$, namely four types.

Similarly seen in equation ( II ), and borrow, the loan have three element options, therefore: $3 \times 3$ $=9$, namely nine kinds of situations, conclusions and accounting consistent, rigorous thinking and flawless but can be hit, but also further in the accounting equation:

Assets $=$ Liabilities + Equity + Profit Assets=Liabilities + Owner rights

Another advantage of the accounting equation (IV) balanced on a good understanding of other accounting elements at the same time, increase revenue (decrease) will cause the owner's equity decrease (increase) of this economic phenomenon. It is very difficult to understand for beginners accounting issues. Because the beginner will come: increase in income means increased profits, increased profits leads to increased ownership interest in this mistaken view.

Management Accounting. Mathematics Calculus important point "on behalf of a straight song" in accounting has also been used, management accounting to calculate investment returns on plan contains a manifestation of this in the calculation of internal rate of return of investment programs, any general Pick two similar discount rate, determined their net present value (NPV preferably a greater than zero, another NPV is less than zero, then the two discount rate closer the better), the establishment of appropriate coordinates, draw two, has had two points in the intersection of line and the $\mathrm{X}$ axis, can be used as internal rate of return of investment program, which is an approximate solution to the exact value, you can use segmentation seeking $1 / 2$ the exact solution,

Financial Management. Business as an accounting entity, one of the purposes of their business is "profitable" and business "profit" in the pursuit are constantly changing. Previous standard enterprise investment scheme selection is profit $(\mathrm{EBIT})>0$; the merits of the measure is to EBIT is greater than zero. And now as more of a measure of the total contribution margin (Tem) $\mathrm{cm}$ or unit contribution margin is greater than 0 , and the progressive development of mathematics is consistent.

Generally considered Tem and EBIT difference fixed costs a, in mathematics a derivative is a constant, the constant is zero, using views of higher mathematics, as a standard to judge the merits of the program should be consistent. But in the accounting analysis that the number of $\mathrm{T}$ cm more advantages.

The use of segmentation theory of knowledge, if we can be unlimited segmentation unit product can be seen, the conditions of feasibility of the program is $\mathrm{cm}>0$, and the best choice is $\mathrm{cm}=0, \mathrm{~cm}=$ $\mathrm{P}-\mathrm{C}$, this and higher mathematics marginal analysis is consistent with one of the necessary conditions for producing the optimal solution is the profit margin to zero, or the marginal cost = marginal revenue. 
From EBIT to change Tem in mathematics from elementary mathematics is breakeven analysis to marginal analysis of higher mathematics, it has developed into modern financial management objectives for the benefit of maximizing shareholder or earnings per share, corresponding to the requirements Mathematical models have new, planning a program to maximize shareholder value.

\section{Development Tendency of Accounting Mathematics}

Mathematics is a subject is-tight, precise thinking tools. Development of socio-economic phenomena is unified both quality and quantity, accounting has its quantitative side, in this development process, the use of mathematical methods as an analytical tool is not only necessary, but also possible. As early as a century ago, Marx pointed out that a science only successful use of mathematics in order to achieve a real improvement in the situation. We must recognize mathematics in many ways to promote the development of accounting.

First prompting Accounting towards quantification, precision, rigor direction, management accounting, cost accounting is very skilful mathematical research methods and accounting combine to form the result of a discipline, new developments in both accounting and also Mathematical methods in economic policy in the use of the extended forecast, so more research is inseparable from the accounting math, that many teachers of the National University accounting department is actually a mathematician, they use advanced mathematical methods, and even professional mathematicians considered to be "difficult" or "very special."

Secondly Mathematics "sharp" the analysis tool, mathematics itself constantly seeking simple proof, but also constantly looking for them to apply the theoretical framework. Mathematics under strict assumptions to draw general conclusions, so that when the decision analysis accounting in big gains, such as from breakeven to balance supply and demand analysis of the development of marginal analysis, elastic analysis, both reveal a logical calculus I thought, just give a simple explanation will change a person's awareness of the issue.

Again mathematics deepen the study of the field of accounting, so that the basic functions of the accounting oversight to participation in economic decision-making, from the current interest, after accounting calculation to predict beforehand future economic benefits; will continue to produce many new theories branch, in the use of each branch of mathematical knowledge is almost a microcosm of the various branches of mathematics, involving elementary mathematics, calculus, linear algebra, probability theory, linear programming.

Cost accounting mathematical brings is huge, it can be said to continue to use mathematical and continue to pay the price. From the concept to learn everyone thinks that people will be able to learn mathematics accounting, so that any problems accounting are trying to explain mathematical methods to study, thus losing the characteristics of accounting itself. The key lies in the huge cost accounting scientist in the study received a value orientation issues mathematicians, that everything can be deduced from the mathematical formula come out, even this can not understand accounting moderate style: "Liabilities = Assets - Owner interest" is not established.

Mathematics can really solve many problems occurring in accounting, but the use of mathematical methods can not solve all the problems, over-relying on mathematical analysis, one of its consequences is ruled out other promising ideas to solve the problem; the second is to establish mathematical model assumptions often made the prediction, decision science cents of difference, loss of a thousand miles; the third is more often than not to show off accounting results, but the mathematical results, and some even to whether to establish a mathematical model whether the use of econometric analysis to determine the outcome of the accounting pros and cons, but never analyzed, considering the accounting value and economic development, so there is no doubt hinder 
the development of mathematical talent is not high, accounting genius, described as too "Mathematics "also defeated" Math."

\section{Conclusion}

As a rigorous mathematical analysis tools, and at the synchronous with accounting development, it creates a new field, set a good foundation and makes enormous contribution to modern accounting. Although it also brings a huge cost, we still don't have reason to refuse mathematics in the accounting, we should advocate for accounting mathematics.

Our effective use of mathematical form method when accounting research conditions are related theory is correct, consistent with relevant premise and reality can assume, for example, accounting for one basic premise: monetary measurement and assuming stable currency. Money that any country are difficult to maintain, and its result is similar to a spring scale to measure the length of one object, measure how much the lack of credibility of the results, especially in the economic turmoil of years, we are more skeptical of the results of accounting. Therefore, the number of hours during the mathematical analysis to consider at this point, can be used to overcome the elastic system, for which there is inflation accounting, this mathematical method is effective.

\section{Reference}

[1] G. Debreu. Mathematical Economic Theory [J]. Foreign Social Sciences, 1991, (9).

[2] Salt Sawada. Mathematical Economics [J]. Foreign Letters And Social Sciences, 1993, (12).

[3] Geng Suohua. On the Cultivation of Advanced Mathematics Students' Thinking Ability [J]. Changchun Gold College, 2001, (1).

[4] Huang Yili. The Development Trend of Accounting Mathematics [J]. 1998(7): 16-19. 